\title{
Promovendo o cuidado para o viver-envelhecer saudável na escola: a educação gerontológica como caminho
}

\author{
Carla Cunha Vaz*, Helenice de Moura Scortegagna**
}

\section{Resumo}

O povo brasileiro, que sempre foi visto como uma população de jovens, vivencia hoje um envelhecimento populacional significativo e acelerado. Esse fenômeno surge como desafio a várias instâncias sociais, diante das necessidades que essa população demanda. Para tanto, a educação tem grande responsabilidade na formação da consciência gerontológica diante da multigeracionalidade social que se configura. Vale ressaltar a necessidade do comprometimento dos educadores e das instituições de ensino, bem como de estimular o interesse das crianças sobre a importância de uma educação para toda a vida, considerando a importância do ser saudável diante da longevidade. Nessa perspectiva, o objetivo desta pesquisa é descrever as percepções de um grupo de escolares sobre a vivência de uma prática educativa de promoção do viver-envelhecer saudável, por meio de um estudo de campo do tipo exploratório e descritivo, com abordagem qualitativa. A pesquisa foi realizada em um subprojeto do projeto integrado "Educação gerontológica como estratégia promotora da interação multigeracional para o viver e envelhecer saudável", a partir de atividades que promoveram a mobilização do conhecimento prévio e de novos aprendizados, a compreensão da vida para além dos limites da sala de aula e o lúdico como interface entre refletir e agir. Conclui-se que as discussões da temática, por meio de práticas educativas, permitiram trazer para os alunos o envelhecer como parte do viver de uma forma divertida, própria para a fase da infância. Os escolares manifestaram a compreensão sobre a importância do cuidado compartilhado e a necessidade da busca do ser saudável em todas as etapas da vida.

Palavras-chave: Envelhecimento. Educação. Cuidado. Enfermagem.

\section{Introdução}

O envelhecimento populacional faz parte da realidade contemporânea, sendo observado no contexto de muitas

\footnotetext{
* Acadêmica de Enfermagem da Universidade de Passo Fundo. Bolsista Probic - Fapergs do projeto de pesquisa "Educação gerontológica como estratégia promotora da interação multigeracional para o viver e o envelhecer saudável". E-mail: carlacunha2@hotmail.com

** Doutora em Enfermagem pela Universidade Federal de Santa Catarina - UFSC. Enfermeira, graduada pela Universidade de Passo Fundo. Professora do curso de Enfermagem da UPF. E-mail: helenice@upf.br
}

$\rightarrow$ http://dx.doi.org/10.5335/rbceh.v12i1.4193

Recebido em: 25/08/2014. Aceito em: 13/03/2015 
famílias e da maioria das sociedades. Nesse sentido, as estimativas para o ano de 2050 são de que existirão cerca de 2 bilhões de pessoas com sessenta anos ou mais no mundo, a maioria delas vivendo em países em desenvolvimento (BRASIL, 2006).

O Brasil sempre foi visto como um país de população jovem, mas vivencia hoje um envelhecimento populacional significativo e acelerado, assim, como o mundo todo, que está envelhecendo cada dia mais. O Brasil, seguindo a tendência mundial, se apresenta hoje, segundo Veras (2009), como um "país jovem de cabelos brancos". A expectativa brasileira é de que existirão mais idosos do que crianças abaixo de quinze anos, fato esse nunca antes observado. No Brasil, segundo dados do IBGE, estima-se que existam, atualmente, 20,5 milhões de idosos, representando $10,8 \%$ da população total (IBGE, 2011).

Küchemann (2012) afirma que o Brasil é um país que envelhece a passos largos. As alterações na dinâmica populacional são claras, inequívocas e irreversíveis. Desde os anos 1940, é entre a população idosa que se observam as taxas mais altas de crescimento populacional.

Até 2025, segundo a Organização Mundial da Saúde (WHO, 2005), o Brasil será o sexto país do mundo em número de idosos. Em todo o mundo, a proporção de pessoas com sessenta anos ou mais está crescendo mais rapidamente que a de qualquer outra faixa etária. Entre 1970 e 2025, espera-se um crescimento de $223 \%$, ou em torno de 694 milhões, no número de pessoas idosas. Assim, em 2025, existirá um total de aproximadamente 1,2 bilhões de pessoas com mais de sessenta anos. Até 2050 haverá dois bilhões, sendo $80 \%$ nos países em desenvolvimento.

Nesse contexto, a saúde tem se mostrado um elemento central por exercer forte impacto sobre a qualidade de vida da população idosa. Questões relacionadas ao reconhecimento dos mais velhos, normalmente associadas ao processo de envelhecimento humano, têm como um de seus pilares o declínio biológico, ocasionalmente acompanhado de doenças e dificuldades funcionais com o avançar da idade (BRASIL, 2010).

Para obter qualidade de vida, sabe-se que a adoção de estilos saudáveis e a participação ativa no cuidado da própria saúde são importantes em todos os estágios da vida. Um dos mitos do envelhecimento é sobre ser tarde demais para se adotar esses estilos nos últimos anos de vida. Ao contrário disso, o envolvimento em atividades físicas adequadas, a alimentação saudável, a abstinência de fumo e álcool, e o uso regulado de medicamentos podem prevenir as doenças e 0 declínio funcional, aumentando, assim, a longevidade e a qualidade de vida do indivíduo (WHO, 2005).

Pode-se ressaltar, também, que a educação é o caminho para o desenvolvimento do homem e da sociedade. Ela é a principal estratégia da identidade cultural na busca da humanização da realidade e da vida, melhorando as condições de vida humana. Para envelhecer bem, entre outros fatores, interagem os estados de saúde, ânimo e positividade, assim como a atitude otimista diante da 
vida. Tudo isso ressalta a importância de uma educação para toda a vida e, mais especificamente, a necessidade de uma educação voltada para a velhice (BOTH, 2006).

Zanon, Alves e Cardenas (2011) concordam com Both (2006), evidenciando que a educação busca o desenvolvimento integral e harmônico da pessoa, e os conteúdos escolares se tornam mais significativos na medida em que se situam em um tempo e espaço concretos de transformações de valores essenciais para a convivência. Os princípios voltados ao diálogo, que propiciam a dignidade, não podem ter fronteiras, devem transpassar todos os conteúdos escolares. Esses são justamente os conteúdos transversais. Assim, é possível entender que a educação gerontológica deve fazer parte do currículo escolar e pode ser trabalhada transversalmente, como já são desenvolvidos os temas transversais que compõem os Parâmetros Curriculares Nacionais (PCNs) (ZANON; ALVES; CARDENAS, 2011).

Acreditando que a escola tenha um compromisso social na formação de um ser saudável, contribuindo significativamente na formação do indivíduo, e considerando que o enfermeiro tem como objetivo essencial promover o cuidado e a saúde do ser humano, é possível que esse profissional busque refletir com os escolares as ações educativas promovidas no cotidiano escolar, buscando a viabilidade de uma educação voltada para a saúde e o bem-estar, com vistas a uma vida longeva. $\mathrm{O}$ envelhecimento surge como um desafio a várias instâncias sociais, diante das necessidades que a parcela idosa da população demanda. Por isso, a educação tem grande responsabilidade na formação do cidadão, da consciência gerontológica diante da multigeracionalidade social, devendo oportunizar aos escolares a reflexão acerca de longevidade, saúde e bem-estar.

Considerando a longevidade humana e a responsabilidade da escola diante desse fenômeno social, e acreditando que uma educação gerontológica participativa e transformadora é o caminho, levanta-se a seguinte questão: como práticas educativas, desenvolvidas na sala de aula podem contribuir para a formação de hábitos pessoais e sociais em prol do viver e do envelhecer numa perspectiva de saúde e cuidado ao olhar dos escolares? É nesse sentido que o objetivo deste estudo é descrever as percepções de um grupo de escolares sobre a vivência de uma prática educativa de promoção do viver e do envelhecer saudáveis.

\section{Metodologia}

Este trabalho caracteriza-se como um estudo de campo do tipo exploratório e descritivo, com uma abordagem qualitativa. É também um subprojeto do projeto integrado "Educação gerontológica como estratégia promotora da interação multigeracional para o viver e envelhecer saudável", aprovado pelo Comitê de Ética da Universidade de Passo Fundo, com parecer: 467.889 e CAAE: 22094513.4.0000.5342.

A investigação foi desenvolvida em uma escola pública de ensino fundamental do município de Passo Fundo, e os sujeitos deste estudo foram escolares matriculados 
no quarto ano dessa escola. A entrada no campo se deu após a autorização da escola, mediante a assinatura do Termo de Consentimento Livre e Esclarecido pelos pais dos alunos. $\mathrm{O}$ estudo atendeu os preceitos éticos da Resolução nํㅜ 466/2012 do Conselho Nacional de Saúde, do Ministério da Saúde (BRASIL, 2012).

A turma composta de vinte alunos caracteriza-se pela faixa etária entre nove e onze anos de idade; dividida quanto ao gênero em partes iguais, sendo dez meninas e dez meninos. O grau de instrução dos pais é predominantemente o ensino fundamental incompleto, já o grau de instrução das mães apareceu como maioria o ensino médio completo. As atividades e profissões dos pais variaram entre: ferreiro, operador de caixa, carpinteiro, agricultor, motorista e mecânico; e das mães, variaram entre: do lar, doméstica, camareira, agricultora e manicure. A maioria das famílias possui casa própria, e todas as crianças convivem ou moram com pais, irmãos e avós, e uma das crianças reside com a bisavó. A renda familiar variou entre meio salário e dois salários mínimos.

A coleta dos dados se deu por meio da realização de prática educativa realizada com os escolares, utilizando-se as oficinas como estratégia de reflexão e diálogo. As oficinas, que se valeram do lúdico, tiveram seu enfoque na temática de viver e envelhecer saudável e foram programadas para estimular a reflexão do escolar quanto à sua realidade e ao seu compromisso pessoal e social diante de um viver-envelhecer com saúde, bem-estar e cuidado.
Os encontros ocorreram duas vezes por semana, no período de março a abril de 2014, com duração de quatro horas em cada encontro. A organização e o planejamento das oficinas seguiram a metodologia de Scortegagna (2006), que prevê a flexibilidade, pois uma oficina pode subsidiar a outra. As oficinas foram estruturadas e desenvolvidas da seguinte forma: tema, apresentado por meio da utilização criativa de dinâmicas para sensibilização; objetivo, articulado com o tema e sua reflexão; técnica, utilizando diversos recursos para o desenvolvimento da oficina, no intuito de atingir o objetivo proposto; avaliação da oficina e encerramento. $\mathrm{O}$ método de operacionalização, considerando a estrutura, foi constituído de momentos, cada momento com um tempo específico e cronometrado.

As oficinas realizadas com os alunos durante esse período envolveram atividades como produção textual, histórias em quadrinhos, confecção de crachás, poemas, histórias de vida, realização de cartazes com recorte e colagem, pinturas; vídeos, dinâmicas, visualização de gravuras, fotos e objetos; filmes, músicas para refletir, entrevistas, recordações; alongamentos, danças, diálogos e questionamentos sobre o tema.

O material de análise foi composto pelos registros da pesquisadora, reunidos em um diário de campo, objetivos e subjetivos, relativos à participação dos escolares nas oficinas e as suas expressões. E, ainda, a percepção dos escolares sobre as oficinas, obtida em registros efetuados por eles na avaliação individual realizada após cada encontro e em uma 
oficina específica para encerramento e avaliação de todos os encontros. Com as questões para avaliação, pretendeu-se verificar o que o escolar compreendeu do encontro; qual a atividade que mais gostou e a que menos gostou; o que foi novidade e o que significou o momento.

A estratégia de análise escolhida foi a proposta por Minayo (2010) de análise temática, que permitiu a elaboração das categorias: mobilização do conhecimento prévio e de novos aprendizados; compreensão da vida para além dos limites da sala de aula; o lúdico como interface entre refletir e agir.

\section{Resultados e discussão}

\section{Breve relato das oficinas}

$\mathrm{O}$ primeiro encontro iniciou com a apresentação da pesquisadora e a exposição do tema que seria trabalhado. Para os escolares, o tema foi motivo de espanto e estranheza, deixando-os muito curiosos e atentos. $\mathrm{Na}$ sequência do encontro, os escolares também se apresentaram.

Depois, ao receberem os crachás, os alunos faziam comentários sobre o que estavam pensando: "eu não vou me desenhar velha, porque eu não quero ser velha, os velhos são doentes, perdem os dentes, tem que usar chapa, eles são chatos, e ficam gordos"; "eu vou ser uma velha feia, de coque na cabeça"; "eu vou usar bengala"; "eu não quero ser igual o meu avô que anda corcunda e usa muleta"; "eu vou ser um velho bem divertido, vou andar de moto e usar um chapéu de gaúcho"; "eu não quero ser velho, velhos precisam tomar remédio"; "velhos ficam na cama deitados".
Foi possível verificar que a maioria dos alunos expressou uma percepção negativa sobre envelhecimento, vinda de suas próprias vivências com idosos em situações de enfermidades. Já outros, embora minoria, demonstraram interesse sobre o tema e ficaram curiosos para saber o que iriam fazer no próximo encontro.

No decorrer dos encontros, observou-se crescente interesse e participação da turma em geral, havendo a quebra da resistência inicial. Nesse sentido, foi possível perceber a mudança de comportamento e a vontade crescente da turma de discutir sobre o tema.

Para trabalhar a temática do viver-envelhecer no cotidiano escolar, as oficinas foram organizadas em três grandes eixos: "Ser gente: pensar e fazer"; "Ser gente: descobrir e compreender"; "Ser gente: conviver e compartilhar". As atividades lúdicas escolhidas para o primeiro eixo foram pintura, recorte e colagem, desenvolvidas em três encontros, nos quais os escolares refletiram sobre: " $\mathrm{O}$ que é viver para mim"; "Do que o ser humano necessita para viver"; "Como eu me relaciono com os outros" e "Como eu me relaciono com o meio ambiente".

Para o segundo eixo, também desenvolvido em três encontros, utilizaram-se estratégias de produção textual e confecção de histórias em quadrinhos, em que os escolares expressaram sua compreensão sobre "O que é o envelhecer para mim?”, por meio de desenhos e diálogos, com base na convivência deles com idosos.

No terceiro eixo, as atividades foram desenvolvidas em quatro encontros, que 
se valeram da reprodução de dois vídeos, um filme e uma música, relacionados ao tema proposto.. As tarefas correspondentes ao filme $U p$ - Altas Aventuras permitiram ao escolar expressar-se por meio de desenho e pintura. Os vídeos, que retratavam um grupo de idosos dançando rock e uma idosa dançando salsa de forma vigorosa e dinâmica, surpreenderam os escolares, oportunizando muitas descobertas. A música: Envelhecer, de Arnaldo Antunes, permitiu aos alunos a expressão pela dança, oportunizando um momento de descontração associado ao pensar crítico e reflexivo proposto.

Ao final de cada oficina, a avaliação foi realizada individualmente por meio das questões: O que significou esse momento para você e que descobertas você fez a partir da discussão levantada? Também foi proposto aos escolares, a partir do diálogo reflexivo estabelecido nos encontros, o comprometimento de desenvolver atitudes positivas e o exercício efetivo de hábitos saudáveis.

\section{Mobilização do conhecimento prévio e de novos aprendizados}

O conhecimento prévio trazido pelos escolares foi de grande importância para o desenvolvimento das oficinas, pois, para que se tenha um educar, cuidar e aprender compartilhado, é preciso conhecer as crianças nas suas diferentes realidades e contextos. Pode-se observar que a construção do significado da velhice para alguns escolares se faz de acordo com o seu ambiente de vida e as suas vivências familiares: "envelhecer é ficar igual a minha avó que mora comigo e fica deitada na cama doente"; "é ficar sentado na cadeira de balanço e fazer crochê na frente da TV e ter os cachorros e os gatos ao redor".

Os escolares expressaram a compreensão de velhice, primeiramente, por meio das mudanças observadas no corpo: "Envelhecer para mim é mudar a aparência"; "é ficar bem velhinha e de cabelos brancos"; "é ficar gordo, com rugas no rosto"; "é ficar careca”. Dentre as alterações observadas na velhice, destacam-se as expressões voltadas para as limitações e as doenças, vistas pelos escolares como sinônimo desta etapa da vida: "[envelhecer é] começar a mancar e não poder mais caminhar"; "ficar com dor nas costas"; "quase morrer"; "é ficar tremendo e com feridas nas pernas".

Houve o registro de falas que denotavam a velhice como uma etapa que se opõe à juventude, na qual há maior evidência para as perdas: "eu acho que temos que aproveitar o dia a dia antes de envelhecer porque depois nós não podemos correr, brincar, pular corda e colocar as roupas e o tênis"; "é tão chato ser velho e é muito bom ser novo, porque quando as pessoas são novas elas sonham, brincam, fazem de tudo até lembra o nosso nome. E quando é velho chamam a gente de velho gaga e eu fico irritado". Nesse sentido, é compreensível que seja considerada uma etapa a temer e, consequentemente, rejeitada, como percebe-se na fala do escolar: "envelhecer para mim é uma coisa ruim e chata porque não poderemos mais cuidar dos filhos e dar educação para eles". Esta imagem condiz com a representação social do ser idoso, que perpassa gerações. Nessa direção, Mos- 
quera e Azevedo (2010) salientam que, na sociedade atual, em que é tão importante a imagem, o consumismo é desenfreado e é incessante a busca da eterna juventude, ser velho parece degradante, e por isso o envelhecimento é algo temido.

No decorrer dos encontros, foi possível notar nas falas dos escolares que alguns conceitos sobre velhice já não eram mais os mesmos observados nos primeiros encontros. Os momentos de discussão com o grupo permitiram que alguns escolares mobilizassem um novo conhecimento, associado ao prévio, conforme as falas que emergiram no decorrer das oficinas: "Eu mudei meu pensamento sobre ser idoso, a velhice é natural e faz parte da vida"; "ser velho é um privilégio"; "agora eu quero ser assim um velho saudável”.

Depois de assistirem ao filme $U p$ - Altas Aventuras, os escolares participaram de uma discussão acerca dos sonhos da infância, e se expressaram sobre seus desejos: "eu sonho abrir um pet shopping"; "meu sonho é morar em uma cabana"; "meu sonho é abrir uma oficina"; "ser rica, ir para Paris e ver a torre féu".

As crianças passam a perceber, também, que os sonhos não se desfazem com o envelhecer, e nunca é tarde demais para concretizá-los: "Eu aprendi com o filme que a gente nunca pode desistir dos nossos sonhos, assim como o senhor Frederiksem [personagem do filme] que ficou velhinho, mas foi atrás do sonho dele".

Em seguida, os alunos foram questionados sobre o que eles precisariam fazer para realizar seus sonhos. Dentre as respostas, destaca-se: "é preciso ter saúde", "se alimentar corretamente", "não usar drogas", "não beber cerveja, cachaça"; "praticar exercícios físicos". Igualmente, estudar surgiu como algo tão importante quanto os demais elementos: "para realizar nossos sonhos é preciso estudar, porque sem estudos a gente não consegue nada"; "prestar atenção nas aulas"; "fazer uma faculdade"; "ter um trabalho"; "ler livros, que é a nossa higiene mental". Os escolares perceberam que para realizar seus sonhos precisam passar por etapas, ter algumas atitudes conscientes como não consumir drogas e álcool, e principalmente estudar, pois é nas vivências escolares que eles começam a refletir sobre seu futuro e construir seus sonhos.

Nesse contexto, Locatelli, Bzuneck e Guimarães (2005) destacam que, a partir do momento em que os adolescentes passam a perceber que a escolarização é importante para se ter um futuro de sucesso, eles ficam mais motivados, e essa motivação se inicia pela percepção da facilidade para desempenhar as atividades de uma determinada disciplina. Pode-se afirmar, então, que a escola é fundamental na formação da criança, do adolescente, e contribui significativamente na escolha do caminho a ser seguido.

Após os escolares assistirem aos vídeos de idosos dançando, se iniciou uma discussão e reflexão sobre o quanto se pode manter a força e o vigor físico na velhice, surgiram comentários com expressões de surpresa: "nossa, eu não acredito que ela fez aquilo, ela deve ter muita força"; "daquela idade dançando daquele jeito noooossa, eu também quero 
ser assim"; "que velhinhos loucos"; "eles deixaram os jurados de boca aberta, também, quando que a gente vê os velhos dançando assim, minha avó é dura das pernas e das costas".

Nessa perspectiva, Both (2001) afirma que a criança reconhece nas pessoas mais velhas a possibilidade de existir e desenvolver recursos para uma longevidade sadia, tendo condições para atualizar constantemente o seu projeto existencial, poderá avaliar-se positivamente e saber qual a sua trajetória.

Os alunos ficaram admirados com os vídeos, e isso também trouxe pra eles a compreensão de que na velhice é possível realizar muitas coisas, desde que se mantenha saudável. Para as crianças, é uma novidade ver idosos realizando coisas que eles julgavam, até então, ser exclusivamente para jovens, pois, na realidade deles, no convívio familiar e social, é essa a concepção que se tem.

A compreensão das crianças sobre o envelhecimento não se limitou mais às mudanças físicas que ocorrem, mas foi direcionada para a velhice como um tempo de ganhos também: "ser velho é ter rugas, mas, além disso, é ser sábio, ter experiência sabe... tipo assim, ficar mais maduro".

Percebe-se que cada escolar tem um jeito próprio de perceber o processo de viver e envelhecer saudável, influenciado ou construído de acordo com o conhecimento e as vivências adquiridas no seu ambiente familiar, escolar e sociocultural. Esses dados estão de acordo com os estudos de França, Silva e Barreto (2010), que asseguram que os filhos são influenciados por aspectos sociocultu- rais, e os pais e avós são responsáveis pela transmissão de valores na família e na comunidade. Em muitos casos, as avós exercem papéis muito importantes no desenvolvimento dos mais jovens, e o relacionamento familiar é primordial para a preservação dos padrões de comportamento na sociedade.

Durante as atividades, os alunos identificaram a importância de praticar exercícios físicos para se ter uma boa saúde: "jogar bola, correr e caminhar todos os dias"; "brincar, pular e dançar", assim como a necessidade de ter uma boa alimentação: "tomar bastante água e comer furtas [sic], legumes e verduras"; "dormir bem". Expressaram, ainda, que para ter saúde também é preciso: "Aproveitar a família, ter amigos e respeitá-los"; “Ter bons hábitos de higiene, ter uma boa higiene mental, praticar o hábito da leitura".

Eles reconheceram que, para envelhecer bem, deve-se ter um cuidado desde a infância, e que o envelhecimento é uma etapa natural da vida, pela qual todos passarão. Eles pareceram compreender que devem ter comprometimento com a busca do ser saudável, e que ter um envelhecimento saudável, depende de cada um. Ficou evidente a percepção que eles têm quanto à necessidade de existir cuidado ainda na infância para que seja saudável o processo de viver e envelhecer.

As crianças apresentaram em suas falas a compreensão de que, para viver e envelhecer de modo saudável, é preciso pertencer a um grupo como a família, que é o espelho e a base da criança. Motta et al. (2003) ressalvam, em seus estudos, 
que os cuidados oferecidos pela família constituem estratégias que favorecem o desenvolvimento humano à medida que proporcionam amor, afeto, proteção e segurança, dentro de um espaço de inclusão e acolhimento aos filhos.

A partir do filme $U p$ - Altas Aventuras, também foram discutidos os valores éticos que permeiam as relações no cotidiano familiar e escolar, como a solidariedade e o respeito intergeracional: "com o filme eu aprendi que a gente deve respeitar os velhinhos e todas as pessoas"; "a gente pode ajudar em tudo que eles precisarem"; "eu aprendi que as crianças e os velhos podem ser amigos"; "eu quero ser um escoteiro, e ajudar e respeitar os velhos".

É a partir da infância que se constrói a valoração da pessoa idosa. A proximidade com a velhice e a existência de laços afetivos unem as gerações. Partindo disso, surgem os vínculos afetivos e os sentimentos de solidariedade e compromisso. Assim, é possível construir o cuidado compartilhado. Nessa temática, Scortegagna (2001, p. 46) destaca que "[...] o compartilhar é o repartir, é o trocar, é o dar e receber, num processo em que cada ser doa um pedacinho do seu ser para o outro com o intuito de promover a vida. É nesse compartilhar que o cuidado se faz presente, pois é no interagir que o ser cresce e se desenvolve".

\section{Compreensão da vida para além dos limites} da sala de aula

Durante os diálogos e questionamentos com o grupo, os escolares expressaram que o viver para eles era: "ser feliz"; "ter amigos"; "estar com a família"; "ter saúde"; "brincar"; "ter uma profissão"; "gostar dos animais"; "respeitar os outros"; "dançar, sorrir, ser alegre".

Verifica-se claramente, nas falas das crianças, que o ser humano assim como é individual é também coletivo, e o quanto é importante a formação de vínculos afetivos, quando dizem que "viver é ter amigos, é estar com a família”. Percebe-se que o escolar é capaz de perceber a importância da amizade em sua vida, assim como das relações familiares. A criança encontra na família a base para descobrir o mundo, desenvolver sua personalidade, seus valores, ela entende que faz parte do viver o relacionar-se com os pais, irmãos, colegas e professores, com o mundo da escola e com o mundo da vida.

Surgiu das discussões a compreensão dos escolares de que, para viver, é necessário: "Comida, água", enfim, as necessidades humanas básicas. Porém, eles também referiram que é necessário: "ter amigos"; "fé, felicidade, amor, carinho"; "ter uma namorada"; "trabalhar, ter dinheiro"; "casar"; "ter um carro, uma casa".

Diante disso, é possível perceber que os escolares entendem o viver como algo que vai acontecendo gradativamente, compreendem que esse processo está ligado àquilo que vivenciam no seu dia a dia. Quando expressam que: "o ser humano necessita de felicidade, amor e carinho", percebe-se que estão presentes os valores e sentimentos que adquiriram na convivência familiar e social.

Outra questão referida pelos escolares foi em relação à espiritualidade, que se encontra vinculada ao contexto 
familiar e cultural, expressando que "o ser humano precisa de religião, ir à igreja, ao culto e rezar todas as noites". Eles passam a perceber que é possível, a partir do que se constrói hoje, do conhecimento que se adquire na escola, na família, preparar-se para o futuro. Todavia, é interessante observar que a escola prepara e projeta até a vida adulta, mas e a velhice? Esta questão pode levar ao entendimento sobre a razão de a velhice ser marginalizada, carente de atenção e, muitas vezes, excluída.

O currículo escolar deve abarcar conteúdos que visem à integridade do ser, a educação deve ser voltada para formar o cidadão integralmente, pois, como afirma Morin (2005, p. 11):

Uma educação só pode ser viável se for uma educação integral do ser humano. Uma educação que se dirige à totalidade aberta do ser humano e não apenas a um de seus componentes.

Isso quer dizer que uma educação do futuro deverá abranger o ser humano em todas as suas fases orgânicas de vida: da infância à velhice, ensinando à criança, desde pequena, a compreensão de que um dia também será um ser humano idoso.

A escola é um meio para se alcançar os objetivos de uma vida futura, seja na família ou no trabalho. Dessa forma, o escolar mostra a compreensão da importância de pertencer a um grupo social para que o processo de viver-envelhecer seja saudável. A escola, de maneira geral, foca o ensino na vida adulta, mas, a partir das oficinas, o foco foi estendido para que o escolar pudesse refletir também sobre envelhecimento e velhice.
Nesse contexto, em seu papel de cuidadora e educadora, a enfermeira deve levar a criança a refletir para elaborar e reciclar ideias e conceitos referentes ao envelhecer humano e suas implicações. Por meio do diálogo reflexivo sobre uma situação da realidade, pode-se levar ao desafio da curiosidade, estabelecendo-se um processo de ensino e aprendizagem entre educador e educando (SCORTEGAGNA, 2001).

Assim sendo, foram estimuladas ações para promover a compreensão da vida para além dos limites da sala de aula. Após cada oficina, foi realizado um exercício, a fim de que o aluno levasse tudo aquilo que era discutido na sala de aula para ter uma experiência na família, aplicando no seu dia a dia. Os escolares se comprometeram a realizar uma ação, e a cada encontro eles apresentavam aos colegas o que haviam feito de novo e qual atitude positiva haviam realizado naquela semana.

Vale resaltar que, segundo o caderno Envelhecimento ativo, da OMS,

A qualidade de vida que as pessoas terão quando avós depende, não somente das oportunidades e riscos que experimentarem durante a vida, mas também da maneira como as gerações posteriores irão oferecer ajuda e apoio quando necessário (WHO, 2005, p. 13).

Por meio de história em quadrinhos os escolares apresentaram diálogos da convivência deles com um idoso, e apareceram várias representações positivas da velhice como "velho legal", "velho querido", "velho amigo". As histórias, na sua maioria, representaram as vivências dos escolares com um idoso que brinca, 
joga vídeo game, ensina a andar de bicicleta, etc. Isso mostra a importância da convivência entre a criança e o idoso, da construção de vínculos, apego, carinho, compreensão e respeito entre as gerações.

No estudo de Luchesi, Dupas e Pavarini (2012), realizado com crianças de sete a dez anos de idade, que moravam com idosos há mais de cinco anos, foram apontadas atitudes consideradas positivas das crianças em relação à velhice. Este estudo corrobora as representações trazidas pelos sujeitos desta pesquisa, pois a maioria deles convive com idosos e demonstra atitude positiva em relação ao envelhecimento. Desse modo, observa-se que quando o escolar está inserido em um ambiente afetivo que lhe possibilita solidariedade, aceitação, segurança, valor e apoio, ele passa a ter relações positivas com outras pessoas e com o ambiente.

O tema desenvolvido por meio de uma oficina fez com que os escolares refletissem não apenas sobre o hoje, mas também sobre a vida deles na escola, na família, e as possibilidades na vida social. Possibilitou, também, o olhar deles frente à velhice, tendo como base a realidade que cada um está inserido, sua cultura e seus valores.

\section{0 lúdico como interface entre refletir e agir}

A utilização do lúdico para os escolares contribuiu para um melhor aprendizado e foi um fator importante, pois, além de promover o desenvolvimento cognitivo das crianças, também estimulou a capacidade de observar, refletir e agir sobre o viver e envelhecer saudável.
Oficinas que permitam o diálogo e a ludicidade são necessárias no processo de desenvolvimento humano, nas diferentes etapas da vida, e permitem que os participantes discutam, reflitam, analisem e se posicionem a respeito dos temas trabalhados, possibilitando a conscientização dos sujeitos, ajudando-os a encontrar a sua própria identidade (SCORTEGAGNA, 2006).

França, Silva e Barreto (2010) destacam que a utilização das estratégias didáticas em uma perspectiva lúdica, como parte integrante do processo de ensino-aprendizagem, é fundamental. Nesse sentido, muito mais que uma parte do processo educativo, elas estarão orientando o próprio processo de ensino-aprendizagem.

$\mathrm{Na}$ avaliação final das atividades lúdicas propostas, os escolares citaram praticamente todas as atividades como importantes, mas os vídeos de velhinhos dançando e o filme Up - Altas Aventuras foram os mais citados, e não houve nenhuma atividade mencionada da qual os alunos não tenham gostado. Isso foi possível perceber pela fala de um aluno: "eu gostei de tudo porque foi legal e divertido, a gente aprendia e ao mesmo tempo brincava e se divertia bastante".

Os alunos afirmaram, também, terem aprendido várias novidades: "Para mim foi novidade ver que os velhos podem fazer tudo, dançar, se divertir, brincar e ser velho não é ruim, nem chato"; "que pra ser saudável basta a gente se alimentar bem, fazer atividades físicas, ter uma boa higiene e estudar"; "A novidade pra mim foi todas as aulas, porque a gente fez várias coisas diferentes, e 
antes eu tinha medo de envelhecer, mas agora eu acho que ser velho faz parte da vida, é natural, é ter experiência, sabedoria e é muito bom".

Com isso, conclui-se que para que a relação entre crianças e idosos se desenvolva de maneira saudável, as crianças precisam conhecer o processo de envelhecimento. Nessa perspectiva, a educação gerontológica por meio de oficinas lúdicas com diálogo reflexivo é uma ferramenta fundamental.

\section{Considerações finais}

A partir dos resultados obtidos, pôde-se concluir que as discussões da temática por meio de práticas educativas mostraram aos alunos o envelhecer como parte do viver de uma forma alegre, divertida, adequada para a fase da infância que eles estão vivendo.

Foi constatado que, apesar de no primeiro encontro os escolares terem apresentado algumas percepções negativas sobre o envelhecer, nos encontros subsequentes eles se encontraram motivados e receptivos em relação ao tema abordado. Pormeio da participação ativa nas atividades, os escolares manifestaram a compreensão sobre a importância do cuidado compartilhado e a necessidade da busca por ser saudável em todas as etapas da vida.

Os escolares, de uma forma particular, expressaram o que sabiam com base em suas vivências e realidades socioculturais. A percepção deles frente à prática educativa foi muito positiva, pois eles explanaram o quanto gostaram e aprenderam com as oficinas permeadas pelo lúdico e pelos diálogos reflexivos.

Isso revela que o objetivo proposto para este trabalho foi alcançado, confirmando que por meio de momentos divertidos e prazerosos é possível alcançar grandes aprendizados. Dessa forma, defende-se que a escola é o espaço apropriado para ensinar que o processo de viver-envelhecer pode ser saudável. Assim sendo, sugere-se que sejam desenvolvidos novos estudos que reflitam sobre essa temática, considerando que na escola, muitas vezes, é deixada de lado.

\section{Providing care to live and healthy aging in school: the gerontological education as a way}

\section{Abstract}

Brazil has always been viewed as a population of young people today experiencing significant population and accelerated aging. This phenomenon emerges as a challenge to various social levels, given the needs that this population demand. To do so, education has great responsibility in the formation of the citizen, of gerontological social conscience before multigenerationality. It is worth mentioning the need for a commitment of all educators and institutions to develop children's interest about the importance of an education for life and, more specifically geared towards old age. Thus, the goal of this research is to describe the perceptions of a group of children about the experience of an educational practice to promote healthy living and aging. It is characterized by being a field study, exploratory, descriptive qualitative approach. Subproject of Integrated Project: "Gerontological Education as a promoter 
of multigenerational interaction for the healthy living and aging strategy". Presented as results mobilization of prior knowledge and new learning, understanding of life beyond the confines of the classroom and recreation as interface between reflecting and acting. We conclude that discussions of the subject, through educational practices allowed students to bring the stale as part of living in a fun way, to own the stage of infancy. The students expressed their understanding of the importance of shared care and the necessity of seeking to be healthy at all stages of life.

Keywords: Aging. Health Education. Nursing care.

\section{Referências}

BRASIL. Ministério da Saúde. Conselho Nacional de Saúde. Resolução no 466, de 12 de dezembro de 2012. Aprova as diretrizes e normas regulamentadoras de pesquisas envolvendo seres humanos. Brasília, DF, 2012. Disponível em: <http://conselho.saude. gov.br/resolucoes/2012/Reso466.pdf>. Acesso em: 6 nov. 2013 .

. Ministério da Saúde. Secretaria de Atenção à Saúde. Departamento de Ações Programáticas e Estratégicas. Atenção à saúde da pessoa idosa e envelhecimento. Área Técnica Saúde do Idoso. Brasília, 2010. 44 p. (Série B. Textos Básicos de Saúde) (Série Pactos pela Saúde, 2006, v. 12).

Ministério da Saúde. Secretaria de Atenção à Saúde. Departamento de Atenção Básica. Envelhecimento e saúde da pessoa idosa. Brasília, 2006. (Série A. Normas e Manuais Técnicos) (Cadernos de Atenção Básica, n. 19).

BOTH, Agostinho. Educação gerontológica: posições e proposições. Erechim: São Cristóvão, 2001. 160 p.
Escola e currículo: Para uma Pedagogia da Qualidade de Vida e da Velhice Ativa. In: CASARA, Miriam Bonho; CORTELLETTI, Ivonne Assunta; BOTH, Agostinho. Educação e envelhecimento humano. Caxias do Sul: Educs, 2006. p. 31-44.

FRANÇA, Lucia Helena de Freitas Pinho; SILVA, Alcina Maria Testa Braz; BARRETO, Márcia Simão Linhares. Programas intergeracionais: quão relevantes eles podem ser para a sociedade brasileira? Revista Brasileira de Geriatria e Gerontologia, Rio de Janeiro, v. 13, n. 3, p. 519-531, set./dez. 2010.

IBGE - INSTITUTO BRASILEIRO DE GEOGRAFIA E ESTATÍSTICA. Sinopse do Censo Demográfico de 2010. Rio de Janeiro, 2011. Disponível em: <http://www.ibge.gov. br/home/presidencia/noticias/imprensa/ ppts/0000000402.pdf>. Acesso em: 12 maio 2014.

KÜCHEMANN, Berlindes Astrid. Envelhecimento populacional, cuidado e cidadania: velhos dilemas e novos desafios. Revista Sociedade e Estado, Brasília, v. 27, n. 1, jan./abr. 2012. Disponível em: <http://www. scielo.br/pdf/se/v27n1/09.pdf>. Acesso em: 10 mar. 2014.

LOCATELLI, Adriana Cristine Dias; BZUNECK, José Aloyseo; GUIMARÃES, Sueli Édi Rufini. A Motivação de Adolescentes em Relação com a Perspectiva de Tempo Futuro. Psicologia: Reflexão e Crítica, Porto Alegre, v. 20, n. 2, p. 268-276, 2005.

LUCHESI, Bruna Moretti; DUPAS, Giselle; PAVARINI, Sofia Cristina Iost. Avaliação da atitude de crianças que convivem com idosos em relação à velhice. Revista Gaúcha de Enfermagem, Porto Alegre, v. 33, n. 4, p. 33-40, dez. 2012.

MINAYO, Maria Cecilia de Souza. O desafio do conhecimento: pesquisa qualitativa em saúde. 12. ed. São Paulo: Hucitec, 2010. 269 p.

MORIN, Edgar. Os sete saberes necessários à educação do futuro. 9. ed. São Paulo: Cortez; Brasília: UNESCO, 2005. 
MOSQUERA, Juan José Mouriño; AZEVEDO, Maria Otília Borba. De tempos em tempos os tempos revelam-se: o idoso nos projetos pedagógicos. POIÉSIS - Revista do Programa de Pós-Graduação em Educação, Universidade do Sul de Santa Catarina, Tubarão, v. 3, n. 6, p. 106-120, jul./dez. 2010.

MOTTA, Maria da Graça Corso et al. Família como unidade de desenvolvimento humano e saúde. Ciência, Cuidado e Saúde, Maringá, v. 2, n. 1, p. 24-27, 2003.

SCORTEGAGNA, Helenice de Moura. Oficinas como Estratégia Pedagógica. In: CASARA, Miriam Bonho; CORTELLETTI, Ivonne Assunta; BOTH, Agostinho. Educação e envelhecimento humano. Caxias do Sul: Educs, 2006. p. 45-69.

Vivendo e aprendendo: para um envelhecer saudável. Passo Fundo: UPF Editora, 2001. 130 p.

VERAS, Renato Peixoto. País jovem com cabelos brancos: a saúde do idoso no Brasil. 2. ed. Rio de Janeiro: Relume Dumará; Uerj, 2009. 224 p.

WORLD HEALTH ORGANIZATION - WHO. Envelhecimento ativo: uma política de saúde/ WHO. Tradução de Suzana Contijo. Brasília: Organização Pan-Americana de Saúde, 2005. $60 \mathrm{p}$.

ZANON, Carla Bianca Ferreira Moncaio; ALVES, Vicente Paulo e CARDENAS, Carmen Jansen. Como vai a Educação Gerontológica nas Escolas Públicas do Distrito Federal? Um estudo com idosos e jovens. Revista Brasileira de Geriatria e Gerontologia, Rio de Janeiro, v. 14, n. 3, p. 555-556, 2011. Disponível em: <http://revista.unati.uerj.br/pdf/rbgg/v14n3/ v14n3a14.pdf>. Acesso em: 27 abr. 2014. 